ARTICLE

\title{
Highly mesoporous metal-organic framework assembled in a switchable solvent
}

Li Peng ${ }^{1}$, Jianling Zhang ${ }^{1}$, Zhimin Xue ${ }^{1}$, Buxing Han ${ }^{1}$, Xinxin Sang ${ }^{1}$, Chengcheng Liu $^{1} \&$ Guanying Yang ${ }^{1}$

The mesoporous metal-organic frameworks are a family of materials that have pore sizes ranging from 2 to $50 \mathrm{~nm}$, which have shown promising applications in catalysis, adsorption, chemical sensing and so on. The preparation of mesoporous metal-organic frameworks usually needs the supramolecular or cooperative template strategy. Here we report the template-free assembly of mesoporous metal-organic frameworks by using $\mathrm{CO}_{2}$-expanded liquids as switchable solvents. The mesocellular metal-organic frameworks with large mesopores $(13-23 \mathrm{~nm})$ are formed, and their porosity properties can be easily adjusted by controlling $\mathrm{CO}_{2}$ pressure. Moreover, the use of $\mathrm{CO}_{2}$ can accelerate the reaction for metalorganic framework formation from metal salt and organic linker due to the viscosity-lowering effect of $\mathrm{CO}_{2}$, and the product can be recovered through $\mathrm{CO}_{2}$ extraction. The as-synthesized mesocellular metal-organic frameworks are highly active in catalysing the aerobic oxidation of benzylic alcohols under mild temperature at atmospheric pressure.

\footnotetext{
${ }^{1}$ Beijing National Laboratory for Molecular Sciences, CAS Key Laboratory of Colloid, Interface and Chemical Thermodynamics, Institute of Chemistry, Chinese Academy of Sciences, Beijing 100190, China. Correspondence and requests for materials should be addressed to J.Z. (email: zhangj|@iccas.ac.cn).
} 
$\mathrm{n}$ recent years, metal-organic frameworks (MOFs) have attracted considerable attention because of their diverse fascinating topologies, pore size tenability and extensive uses in lots of fields such as catalysis, adsorption, chemical sensing and so on ${ }^{1-3}$. The construction of hierarchically meso- and microporous MOFs are of great interest, because they provide many novel properties and have important prospects in practical industrial processes ${ }^{4,5}$. The larger mesopores allow for improved molecular accessibility, whereas smaller micropores provide high surface areas. Some methods have been developed for the formation of hierarchically meso- and microporous MOFs, including surfactant-template $\operatorname{method}^{6-9}$, ligand extension method $^{10-14}$, microwave-assisted method ${ }^{15}$, solvent evaporation diffusion method ${ }^{16,17}$, ionic liquid/supercritical $\mathrm{CO}_{2}$ emulsion route $^{18}$ and so on. However, most of the meso-MOFs adopt smaller mesopores $(<5 \mathrm{~nm})$ and the preparation of large-pore meso-MOFs is sporadic at best, which usually needs the supramolecular or cooperative template strategy ${ }^{6,9}$. The augmentation of the MOF mesopores remains to be a major challenge.

Compressed $\mathrm{CO}_{2}$ has received much interest because it is nontoxic, inexpensive, non-flammable, and can be easily recaptured and recycled after use $\mathrm{e}^{19-21}$. In particular, compressed $\mathrm{CO}_{2}$ is quite soluble in many liquids, and can change the properties of the liquids considerably. For example, as $\mathrm{CO}_{2}$ dissolves into an organic solvent, the liquid expands volumetrically, forming a $\mathrm{CO}_{2}$-expanded liquid $(\mathrm{CXL})^{22}$. Therefore, by varying $\mathrm{CO}_{2}$ pressure, a continuum of liquid media ranging from the neat organic solvent to CXL is generated, and their properties can be adjusted by tuning the operating pressure. Until now, CXLs have been shown to be optimal solvents in a variety of fields, including facilitating polymer processing ${ }^{23-26}$, serving as reaction media ${ }^{27-31}$, precipitating fine particles $^{32-34}$, inducing separations ${ }^{35,36}$ and so on.

Herein, we propose the $\mathrm{CO}_{2}$-directed assembly of meso-MOFs. By using CXLs as switchable solvents, the mesocellular MOFs with large mesopores (13-23 nm) and ultra-high mesoporosities are formed. In comparison with the conventional methods for the meso-MOF formation, this strategy has many special advantages. First, the porosity properties of the as-synthesized MOFs can be easily modulated by $\mathrm{CO}_{2}$ pressure. Second, the reaction for MOF formation from metal salt and organic linker can be accelerated by $\mathrm{CO}_{2}$ due to the viscosity-lowering effect of $\mathrm{CO}_{2}$. Third, the product can be recovered through extracting the solvent by $\mathrm{CO}_{2}$. Fourth, $\mathrm{CO}_{2}$ can be easily removed by reducing pressure. In addition, this method for the meso-MOF formation is
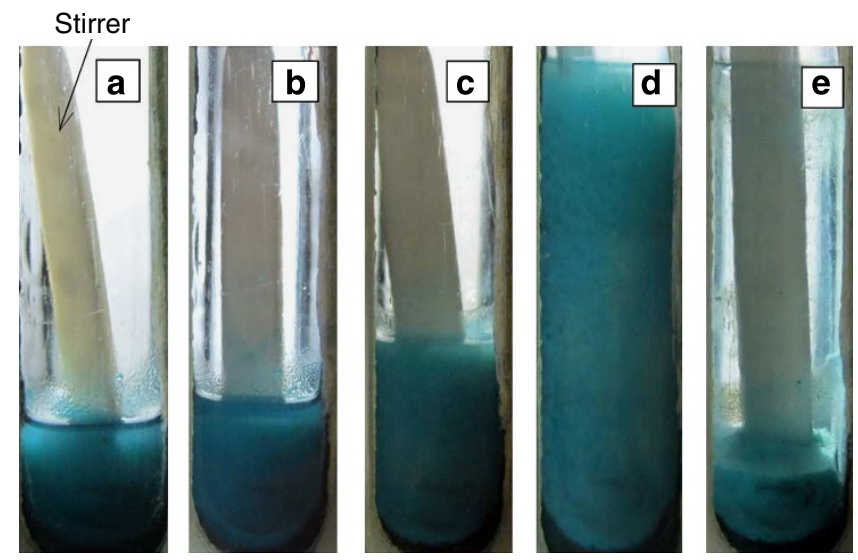

Figure 1 | Photographs of MOF synthesis in $\mathbf{C O}_{2}$-expanded DMF.

(a) In pure DMF; (b) 2.0; (c) 4.5; (d) $6.6 \mathrm{MPa}$. (e) Phase separation in reaction system at $6.6 \mathrm{MPa}$ after reaction for $3 \mathrm{~h}$. template-free, involves no longer ligand, proceeds at room temperature and can be applied to the synthesis of different kinds of MOFs. The mesocellular MOFs have shown to be highly effective and reusable heterogeneous catalysts for aerobic oxidation of benzylic alcohols under mild temperature at atmospheric pressure.

\section{Results}

Volume expansion of the reaction system by $\mathrm{CO}_{2}$. $\mathrm{Cu}_{3}(\mathrm{BTC})_{2}\left(\mathrm{H}_{2} \mathrm{O}\right)_{3} \cdot x \mathrm{H}_{2} \mathrm{O}(\mathrm{BTC}=1,3,5$-benzenetricarboxylate $)$ is one of the most extensively explored MOFs for its various uses ${ }^{6,9,37-39}$. Herein we synthesized $\mathrm{Cu}_{3}(\mathrm{BTC})_{2}$ in $\mathrm{CO}_{2}$-expanded $\mathrm{N}, \mathrm{N}$-dimethylformamide (DMF) at $30^{\circ} \mathrm{C}$, using copper(II) acetate monohydrate $\left(\mathrm{Cu}(\mathrm{OAc})_{2} \cdot \mathrm{H}_{2} \mathrm{O}\right)$ and benzene-1,3,5tricarboxylic acid $\left(\mathrm{H}_{3} \mathrm{BTC}\right)$ as $\mathrm{MOF}$ precursors. A certain amount of triethylamine was added into the reaction system to deprotonate the linker. Figure 1 shows the photographs of the reaction systems in pure DMF (Fig. 1a) and $\mathrm{CO}_{2}$-expanded DMF at different pressures (Fig. $1 \mathrm{~b}-\mathrm{d}$ ). Evidently, the reaction system was expanded with the addition of $\mathrm{CO}_{2}$ and the volume expansion increased at higher pressure. After $3 \mathrm{~h}$ of reaction the stirring was stopped. The product separated out from the solvent naturally and precipitated at the bottom of the autoclave (Fig. 1e). Then the upper solvent was extracted by flowing $\mathrm{CO}_{2}$, and the product precipitated at the bottom of the autoclave was recovered and washed using ethanol.

Mesoporous $\mathrm{Cu}_{3}(\mathrm{BTC})_{2}$ synthesized in $\mathrm{CO}_{2}$-expanded DMF. The $\mathrm{Cu}_{3}(\mathrm{BTC})_{2}$ synthesized in pure DMF (in the absence of $\mathrm{CO}_{2}$ ) appeared as irregular agglomerates (Supplementary Fig. 1). However, the mesocellular MOFs were formed in the $\mathrm{CO}_{2}$ expanded DMF. The $\mathrm{Cu}_{3}(\mathrm{BTC})_{2}$ synthesized at $2.0 \mathrm{MPa}$ exhibits a

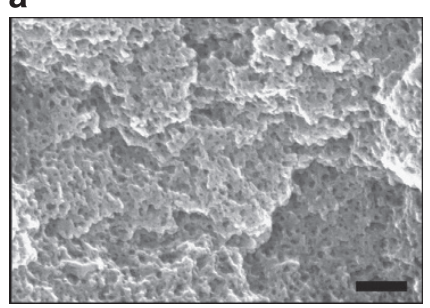

c

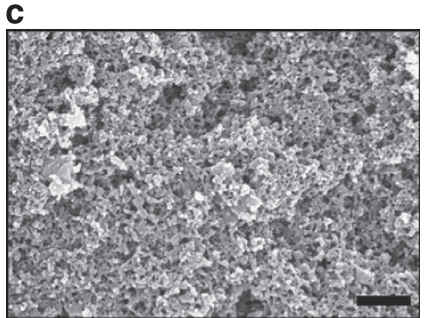

e

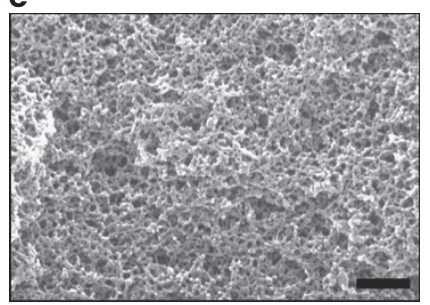

b

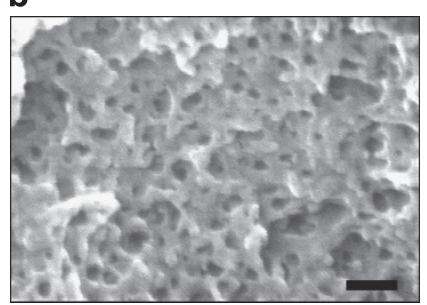

d

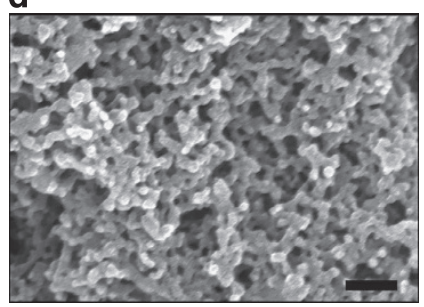

f

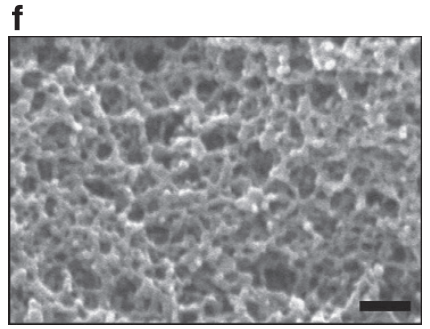

Figure 2 | $\mathrm{SEM}$ images of the $\mathrm{Cu}_{3}(\mathrm{BTC})_{2}$ synthesized in $\mathrm{CO}_{\mathbf{2}}$-expanded DMF. (a,b) 2.0; (c,d) 4.5; (e,f) 6.6 MPa. Scale bars, 150, 50, 500, 150, 500 and $150 \mathrm{~nm}$ for (a-f), respectively. 
thick pore walls and mesopores of average size of $10 \mathrm{~nm}$ (Fig. 2a,b). When the pressure is increased to $4.5 \mathrm{MPa}$, the MOF is more porous, with thinner mesopore walls (Fig. 2c,d). The $\mathrm{Cu}_{3}(\mathrm{BTC})_{2}$ synthesized at $6.6 \mathrm{MPa}$ has mesopores in $20-30 \mathrm{~nm}$ and the diameters of the pore walls are around $10 \mathrm{~nm}$ (Fig. 2e,f). Clearly, higher $\mathrm{CO}_{2}$ pressure is favourable to form more porous MOFs, with larger mesopores and thinner pore walls. The X-ray diffraction (XRD) peak positions and relative intensities of the assynthesized MOFs agree well with those of the simulated HKUST-1 (ref. 37; Supplementary Fig. 2). Fourier transform infrared spectra (Supplementary Fig. 3) revealed that the carboxylate groups of $\mathrm{H}_{3}$ BTC were coordinated to $\mathrm{Cu}$ (II) ions ${ }^{9,18,40}$. The characteristic $\mathrm{C}=\mathrm{O}$ stretching vibration for acetic acid $\left(1,770-1,750 \mathrm{~cm}^{-1}\right)$ and $\mathrm{C}-\mathrm{N}$ stretching vibration $(1,230-$ $\left.1,030 \mathrm{~cm}^{-1}\right)$ for triethylamine were not observed, indicating that the product is free of acetic acid and triethylamine, which could be removed easily by washing with ethanol. Energydispersive X-ray spectrum (Supplementary Fig. 4) demonstrates the presence of copper, oxygen and carbon in the prepared MOF and no $\mathrm{N}$ element was detected, further proving the absence of triethylamine in the product. The MOFs could keep stable up to $310^{\circ} \mathrm{C}$, as evidenced by thermogravimetric analysis (Supplementary Fig. 5), comparable to that of bulk HKUST-1 (refs 41,42).

Porosity properties of $\mathrm{Cu}_{3}(\mathrm{BTC})_{2}$. The porosity properties of the $\mathrm{Cu}_{3}(\mathrm{BTC})_{2}$ were determined by $\mathrm{N}_{2}$ adsorption-desorption
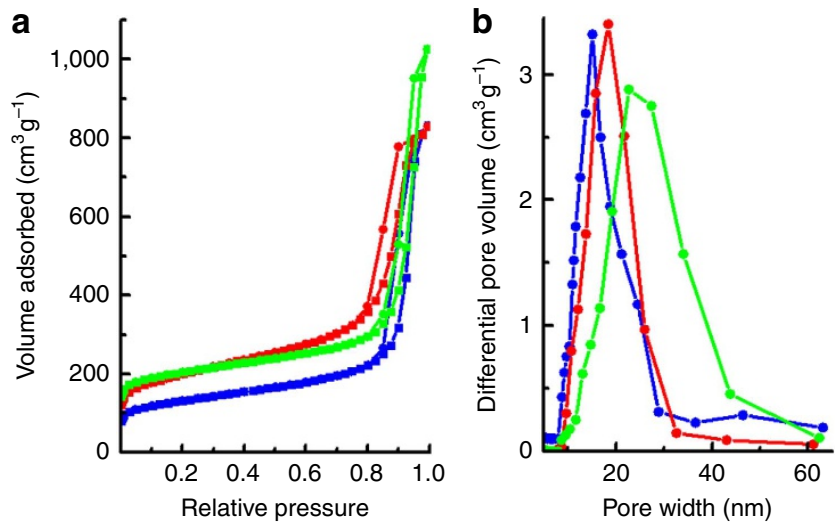

Figure 3 | Porosity measurements. Porosity properties of $\mathrm{Cu}_{3}(\mathrm{BTC})_{2}$ determined by $\mathrm{N}_{2}$ adsorption-desorption method. (a) $\mathrm{N}_{2}$ adsorptiondesorption isotherms of the $\mathrm{Cu}_{3}(\mathrm{BTC})_{2}$ synthesized in $\mathrm{CO}_{2}$-expanded $\mathrm{DMF}$ at 2.0 MPa (blue curves), 4.5 MPa (red curves) and 6.6 MPa (green curves). (b) The mesopore size distribution curves for the $\mathrm{Cu}_{3}(\mathrm{BTC})_{2}$ synthesized under the same conditions. method after the sample was dried and degassed at $100^{\circ} \mathrm{C}$. Figure 3a shows the $\mathrm{N}_{2}$ adsorption-desorption isotherms of the $\mathrm{Cu}_{3}(\mathrm{BTC})_{2}$ synthesized in $\mathrm{CO}_{2}$-expanded DMF at different pressures. They exhibit an intermediate mode between type I and type IV, which are related to mesoporous and microporous materials, respectively. The mesopore size distribution curves, calculated from Barrett-Joyner-Halenda analysis, are shown in Fig. 3b. The mesopore diameters of the $\mathrm{Cu}_{3}(\mathrm{BTC})_{2}$ synthesized at 2.0, 4.5 and $6.6 \mathrm{MPa}$ are centred at 13,20 and $23 \mathrm{~nm}$, respectively. Evidently, higher $\mathrm{CO}_{2}$ pressure favours the formation of larger mesopores, which is consistent with the scanning electron microscopic (SEM) observations. From $\mathrm{N}_{2}$ adsorptiondesorption isotherm, the diameter of the micropores was calculated to be $0.85 \mathrm{~nm}$ by Horvath-Kawazoe analysis (Supplementary Fig. 6), in agreement with the micropore diameter estimated from crystallographic data of $\mathrm{Cu}_{3}(\mathrm{BTC})_{2}$ (ref. 37). The porosity properties of the MOFs were further characterized by small-angle X-ray scattering (SAXS) and the results are shown in Supplementary Fig. 7. The SAXS profiles (Supplementary Fig. 7A) display power law scattering of $\mathrm{Q}^{-4}$ in the low $\mathrm{Q}$ region $\left(\mathrm{Q}<0.08 \AA^{-1}\right)$, corresponding to the asymptotic scattering behaviour of mesopores ${ }^{43}$. The mesopore size distributions of the MOFs synthesized at pressure of 2.0, 4.5 and 6.6 $\mathrm{MPa}$ were calculated, which are centred at about 13.8, 19.0 and $21.1 \mathrm{~nm}$ (Supplementary Fig. 7B). These results are consistent with the mesopore size distributions obtained from $\mathrm{N}_{2}$ adsorption-desorption. The results prove the formation of hierarchically meso- and microporous MOFs in CXL and the mesopore size can be easily tuned by varying pressure.

The surface areas and pore volumes of the hierarchically porous $\mathrm{Cu}_{3}(\mathrm{BTC})_{2}$ synthesized in $\mathrm{CO}_{2}$-expanded $\mathrm{DMF}$ at different pressures are listed in Table 1, as identified from the $\mathrm{N}_{2}$ adsorption-desorption isotherms. The BET (Brunauer, Emmett and Teller) surface area $\left(S_{\mathrm{BET}}\right)$ values of the three MOFs are not very high $\left(\sim 700 \mathrm{~m}^{2} \mathrm{~g}^{-1}\right)$, which can be ascribed to the pore impenetration ${ }^{44}$. The total pore volumes $\left(V_{\mathrm{t}}\right)$ of the three MOFs are rather high $\left(>1.28 \mathrm{~cm}^{3} \mathrm{~g}^{-1}\right)$. The micropore volume is around $0.2 \mathrm{~cm}^{3} \mathrm{~g}^{-1}$, while the mesopore volume $\left(V_{\text {meso }}\right)$ accounts for about $85 \%$ of the total pore volume of the MOFs. As far as we know, the MOFs synthesized in $\mathrm{CO}_{2}$-expanded DMF represent the largest mesopore volume value among the reported meso-MOFs (usually in the range of $0.1-0.5 \mathrm{~cm}^{3} \mathrm{~g}^{-1}$ ). The ultra-high mesopore volumes of the as-synthesized $\mathrm{Cu}_{3}(\mathrm{BTC})_{2}$ result from their mesocellular structure. Moreover, Table 1 shows that the mesopore volume of the MOF synthesized in $\mathrm{CO}_{2}$-expanded $\mathrm{DMF}$ at higher pressure is larger, suggesting that more $\mathrm{CO}_{2}$ dissolved in DMF is favourable to form mesopores in MOF. Materials with high pore volume as well as large mesopores would be of importance for their applications in diverse fields such as catalysis, drug delivery, separation and energy storage.

Table 1 | Porosity properties of the $\mathrm{Cu}_{3}(\mathrm{BTC})_{2}$ synthesized in CXLs.

\begin{tabular}{|c|c|c|c|c|c|c|}
\hline Liquids & Pressure (MPa) & $S_{\mathrm{BET}^{\star}}\left(\mathrm{m}^{2} \mathrm{~g}^{-1}\right)$ & $S_{\text {meso }}^{\dagger}\left(m^{2} g^{-1}\right)$ & $V_{t}^{\ddagger}\left(\mathrm{cm}^{3} \mathrm{~g}^{-1}\right)$ & $V_{\text {meso }}{ }^{\S}\left(\mathrm{cm}^{3} \mathrm{~g}^{-1}\right)$ & $D_{\text {meso }}$ I (nm) \\
\hline DMF & 2.0 & 671 & 330 & 1.283 & 1.102 & 13 \\
\hline DMF & 4.5 & 687 & 334 & 1.385 & 1.173 & 20 \\
\hline DMF & 6.6 & 728 & 366 & 1.586 & 1.356 & 23 \\
\hline DMA & 4.5 & 480 & 223 & 1.147 & 1.009 & 17 \\
\hline NMP & 4.5 & 445 & 218 & 0.757 & 0.634 & 13 \\
\hline
\end{tabular}

${ }^{*} S_{B E T}$ is the BET-specific surface area.

$\dagger S_{\text {meso }}$ is the specific mesopore surface area estimated by subtracting $S_{\text {micro, }}$ the t-plot-specific micropore surface area calculated from the $N_{2}$ adsorption-desorption isotherm from $S_{B E T}$.

$\ddagger V_{t}$ is the total specific pore volume determined by using the adsorption branch of the $N_{2}$ isotherm at $P / P_{0}=0.99$.

$\$ V_{\text {meso }}$ is the specific mesopore volume obtained from the $\mathrm{BJH}$ cumulative specific adsorption volume

\|The mesopore diameter is estimated from the local maximum of BJH pore size distribution obtained in the desorption branch of $\mathrm{N}_{2}$ isotherm. 


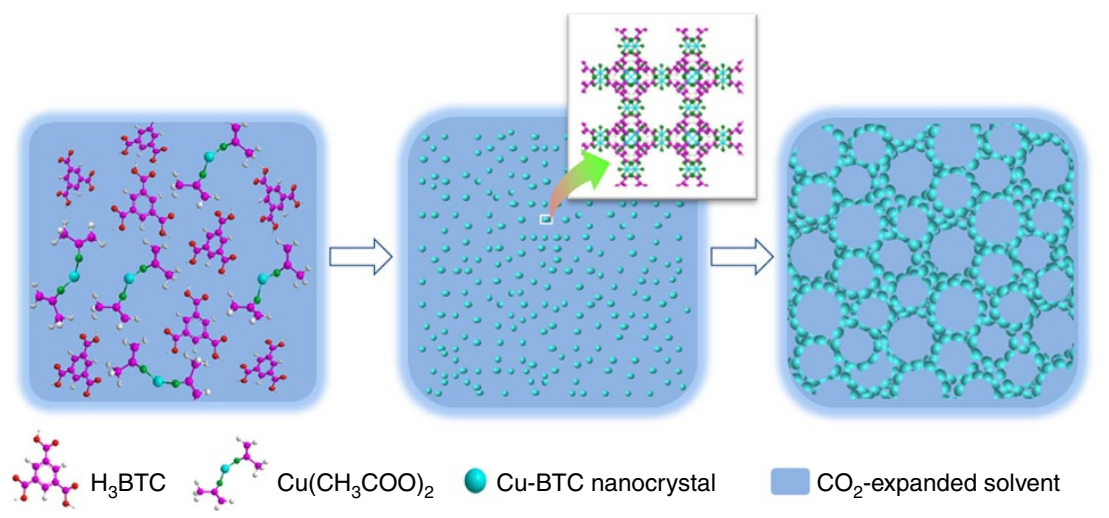

Figure 4 | Schematic illustration for mesocellular MOF formation. The $\mathrm{Cu}^{2+}$ ions react with the deprotonated $\mathrm{BTC}^{3-}$ in the $\mathrm{CXL}$ and the nanosized framework building blocks are produced. Then the MOF building blocks assemble to form the mesocellular MOFs with large mesopores and thin mesopore walls.
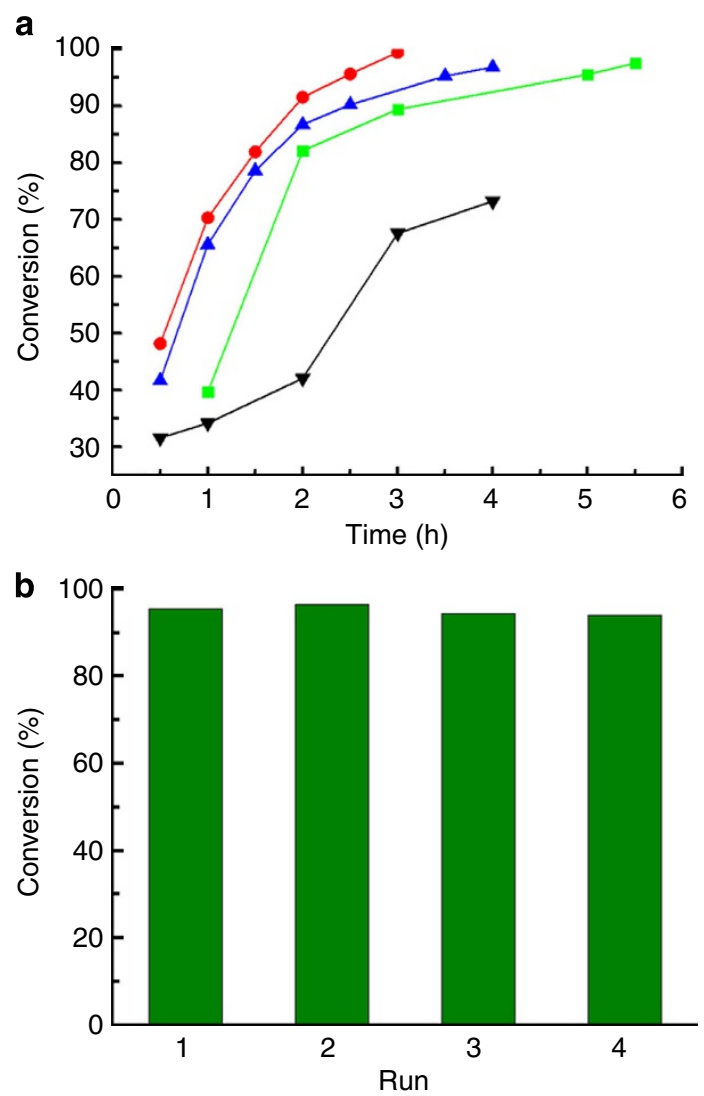

Figure 5 | Oxidation of benzyl alcohol using $\mathrm{Cu}_{3}(\mathrm{BTC})_{2}$ with oxygen. (a) Time conversion plot for the aerobic oxidation of benzyl alcohol to benzaldehyde catalyzed by the $\mathrm{Cu}_{3}(\mathrm{BTC})_{2}$ synthesized in $\mathrm{CO}_{2}$-expanded DMF at 2.0 MPa (green curve), 4.5 MPa (blue curve), 6.6 MPa (red curve) and in pure DMF (black curve). Reaction conditions: benzyl alcohol $0.185 \mathrm{mmol}$, catalyst $30 \mathrm{mg}$, DMF $1 \mathrm{ml}$, TEMPO (0.5 equiv), $\mathrm{Na}_{2} \mathrm{CO}_{3}$ (1 equiv), $75^{\circ} \mathrm{C}$, oxygen atmosphere. (b) The reusability of the $\mathrm{Cu}_{3}(\mathrm{BTC})_{2}$ synthesized in $\mathrm{CO}_{2}$-expanded DMF at 6.6 MPa.

Mesoporous $\mathrm{Cu}_{3}(\mathrm{BTC})_{2}$ synthesized in other CXLs. Furthermore, the $\mathrm{Cu}$-BTC MOFs were synthesized in $\mathrm{CO}_{2}$-expanded $\mathrm{N}, \mathrm{N}$-dimethylacetamide (DMA) and $\mathrm{N}$-methyl-2-pyrrolidone (NMP) at $4.5 \mathrm{MPa}$, respectively. They both have a large-pore mesoporous structure (see SEM images, XRD patterns and $\mathrm{N}_{2}$ adsorption-desorption isotherms in Supplementary Figs 8-10), indicating that $\mathrm{CO}_{2}$ is efficient for directing the assembly of mesocellular MOFs in different solvents. As listed in Table 1, the porosity properties and the mesopore size are decreased in the order of DMF $>$ DMA $>$ NMP. To better understand the effect of $\mathrm{CO}_{2}$ on the mesocellular MOF formation, the volume expansions $(\Delta V)$ of the three organic solvents in $\mathrm{CO}_{2}$ were determined. All these solvents can be expanded greatly by $\mathrm{CO}_{2}$, and the $\Delta V$ at the same pressure increases in the order of $\mathrm{NMP}<\mathrm{DMA}<\mathrm{DMF}$ (Supplementary Fig. 11). By combining the results shown in Table 1, evidently, the MOF synthesized in the more expanded liquid has higher porosity and larger mesopores.

Formation mechanism. On the basis of the experimental results, a possible mechanism for the $\mathrm{CO}_{2}$-directed formation of mesocellular MOF is proposed (Fig. 4). First, the $\mathrm{Cu}^{2+}$ ions react with the deprotonated $\mathrm{BTC}^{3-}$ to structure the nanosized framework building blocks ${ }^{39,45}$. Owing to the reduced solvency and viscosity of solvent by $\mathrm{CO}_{2}$ expansion, the microporous MOF building blocks produced in the $\mathrm{CO}_{2}$-expanded solvent are expected to be smaller than those yielded in $\mathrm{CO}_{2}$-free solvent ${ }^{39,45}$, and higher pressure favours the formation of smaller building blocks ${ }^{32-34}$. In a second step, the nanosized MOF building blocks assemble to form the network because smaller particles have higher surface energy $^{46}$, and the assembly of MOF nanocrystals is looser at higher pressure due to the greater expansion of the solvent. Therefore, after removing the solvent and releasing $\mathrm{CO}_{2}$, the mesocellular MOFs with large mesopores and thin mesopore walls are formed. The structural parameters of the MOFs are dependent on $\mathrm{CO}_{2}$ pressure, that is, the higher the $\mathrm{CO}_{2}$ pressure is, the more porous MOF with larger mesopores is formed.

Catalytic activities of $\mathrm{Cu}_{3}(\mathbf{B T C})_{2}$. The $\mathrm{Cu}_{3}(\mathrm{BTC})_{2}$ MOFs synthesized in $\mathrm{CO}_{2}$-expanded DMF were used to catalyse the oxidation of benzyl alcohol to benzaldehyde, using 2,2,6,6tetramethyl-piperidine-1-oxyl (TEMPO) as a co-catalyst ${ }^{47}$. The selectivity of benzaldehyde was $>99 \%$. As shown in Fig. 5a, the $\mathrm{Cu}_{3}(\mathrm{BTC})_{2}$ synthesized at higher pressure is more active. By using the $\mathrm{Cu}_{3}(\mathrm{BTC})_{2}$ synthesized at $6.6 \mathrm{MPa}$, benzyl alcohol converted completely to benzaldehyde at $3 \mathrm{~h}$ (red curve). The activities of the three MOFs are higher than that synthesized in pure DMF (black curve), further much higher than that of commercial $\mathrm{Cu}_{3}(\mathrm{BTC})_{2}$ at the same experimental conditions (10\% conversion at $3 \mathrm{~h})^{47}$. The catalyst shows no evident drop in catalytic activity after four runs (Fig. 5b), indicative of the high stability of the MOF. No notable difference was observed for the XRD patterns and SEM images of the fresh $\mathrm{Cu}_{3}(\mathrm{BTC})_{2}$ and that after being 
reused for four runs (Supplementary Figs 12 and 13), indicating that the structural integrity of the MOF was well preserved. The porosity properties of the $\mathrm{Cu}_{3}(\mathrm{BTC})_{2}$ after being reused for four runs were determined by $\mathrm{N}_{2}$ adsorption-desorption method (Supplementary Fig. 14). The BET surface area of the recycled sample is $685 \mathrm{~m}^{2} \mathrm{~g}^{-1}$, which is slightly lower than that of the original sample $\left(728 \mathrm{~m}^{2} \mathrm{~g}^{-1}\right)$. The mesopore size distribution of the recycled sample is nearly identical with that of the original one. This indicates that the mesoporous structure of the MOF can be well preserved after being reused for four runs. The slight drop of the BET surface area of the recycled MOF may be due to the presence of some inorganic and organic impurities generated during the reaction that blocks the micropore system ${ }^{47}$.

Moreover, the catalytic activities of the as-synthesized mesoporous $\mathrm{Cu}_{3}(\mathrm{BTC})_{2}$ were tested for the aerobic oxidation of various alcohols. The reaction conditions are the same with those for the aerobic oxidation of benzyl alcohol. As can be known from Table 2, 3-nitrobenzyl alcohol, 4-methylbenzyl alcohol and cinnamyl alcohol converted completely to the corresponding aldehydes in 10, 7 and $6 \mathrm{~h}$, respectively (entries $1-3$ ). By contrast, the aldehyde yields catalysed by the commercial microporous $\mathrm{Cu}_{3}(\mathrm{BTC})_{2}$ were 10,65 and $62 \%$ for the three alcohols, respectively, even at a prolonged reaction time of $22 \mathrm{~h}$ (ref. 47). For the oxidation of $3,3^{\prime}, 5,5^{\prime}$-tetrakis(trifluoromethyl)benzhydrol catalysed by the mesoporous $\mathrm{Cu}_{3}(\mathrm{BTC})_{2}$, the $3,3^{\prime}, 5,5^{\prime}$-tetrakis (trifluoromethyl)benzophenone yield reached $57.9 \%$ at $6 \mathrm{~h}$, while that catalysed by the microporous $\mathrm{Cu}_{3}(\mathrm{BTC})_{2}$ was $18.7 \%$ at the same experimental conditions (entry 4). Such high catalytic activities of the $\mathrm{Cu}_{3}(\mathrm{BTC})_{2}$ synthesized in this work can be attributed to their mesocellular structure, which can enhance the diffusion of substrates and products ${ }^{48}$. Also, the nanoscale size of the MOFs is favourable for increasing the density of catalytic active sites ${ }^{49}$, thus accelerating the reaction more efficiently.

Mesoporous Mn MOFs synthesized in CXL. To expand the scope of the CXL for producing mesoporous MOF, we further performed the synthesis of other MOFs in the CXL. The mesoporous $\mathrm{Mn}-\mathrm{BTC}$ and $\mathrm{Mn}-\mathrm{BDC}$ (BDC $=1$,4-benzenedicarboxylate) MOFs were formed in the $\mathrm{CO}_{2}$-expanded DMF (see SEM images and XRD patterns in Supplementary Figs 15 and 16). The average mesopore size of the Mn MOFs is $\sim 20 \mathrm{~nm}$. The results indicate that the CXL is versatile in synthesizing different kinds of mesoporous MOFs.

\section{Discussion}

Here the mesocellular MOFs with large mesopores (13-23 nm) were synthesized in CXL. The porosity properties of the MOFs can be easily adjusted by controlling $\mathrm{CO}_{2}$ pressure. The as-synthesized mesocellular $\mathrm{Cu}_{3}(\mathrm{BTC})_{2} \mathrm{MOFs}$ are effective and reusable heterogeneous catalyst for the aerobic oxidation of benzylic alcohols under mild temperature at atmospheric pressure. By taking advantages of interconnected nature of the large mesopores, these mesocellular MOFs have potential applications in catalysis, gas separation and controlled drug release.

The use of CXL for MOF formation has many advantages, for example, controllable, template-free and involves no longer ligand. It is worth noting that the $\mathrm{Cu}_{3}(\mathrm{BTC})_{2} \mathrm{MOF}$ formation in organic solvent is usually carried out at temperature $70-180^{\circ} \mathrm{C}$ and a reaction time longer than $10 \mathrm{~h}$ is needed ${ }^{6,9,37-39}$. Herein, the reaction in the presence of $\mathrm{CO}_{2}$ proceeded at room temperature and the reaction time was shortened to $3 \mathrm{~h}$. It can be attributed to the enhanced mass transport rates, resulting from the viscosity-lowering effect of $\mathrm{CO}_{2}$ (ref. 22).

Finally, we note that our method can be applied to the synthesis of different kinds of MOFs with large-pore mesoporous structure. Furthermore, we anticipate that the CXL could be used in the in situ production of mesoporous MOFs decorated with highly dispersed metal (or metal oxide) nanoparticles, which will find important applications in catalysis.

\section{Methods}

Materials. $\mathrm{CO}_{2}$ (>99.95\%) was provided by Beijing Analysis Instrument Factory DMF and trifluoroacetate were provided by Beijing Chemical Reagent Company.

Table 2 | Oxidation of alcohols using $\mathrm{Cu}_{3}(\mathrm{BTC})_{2}$ with oxygen.

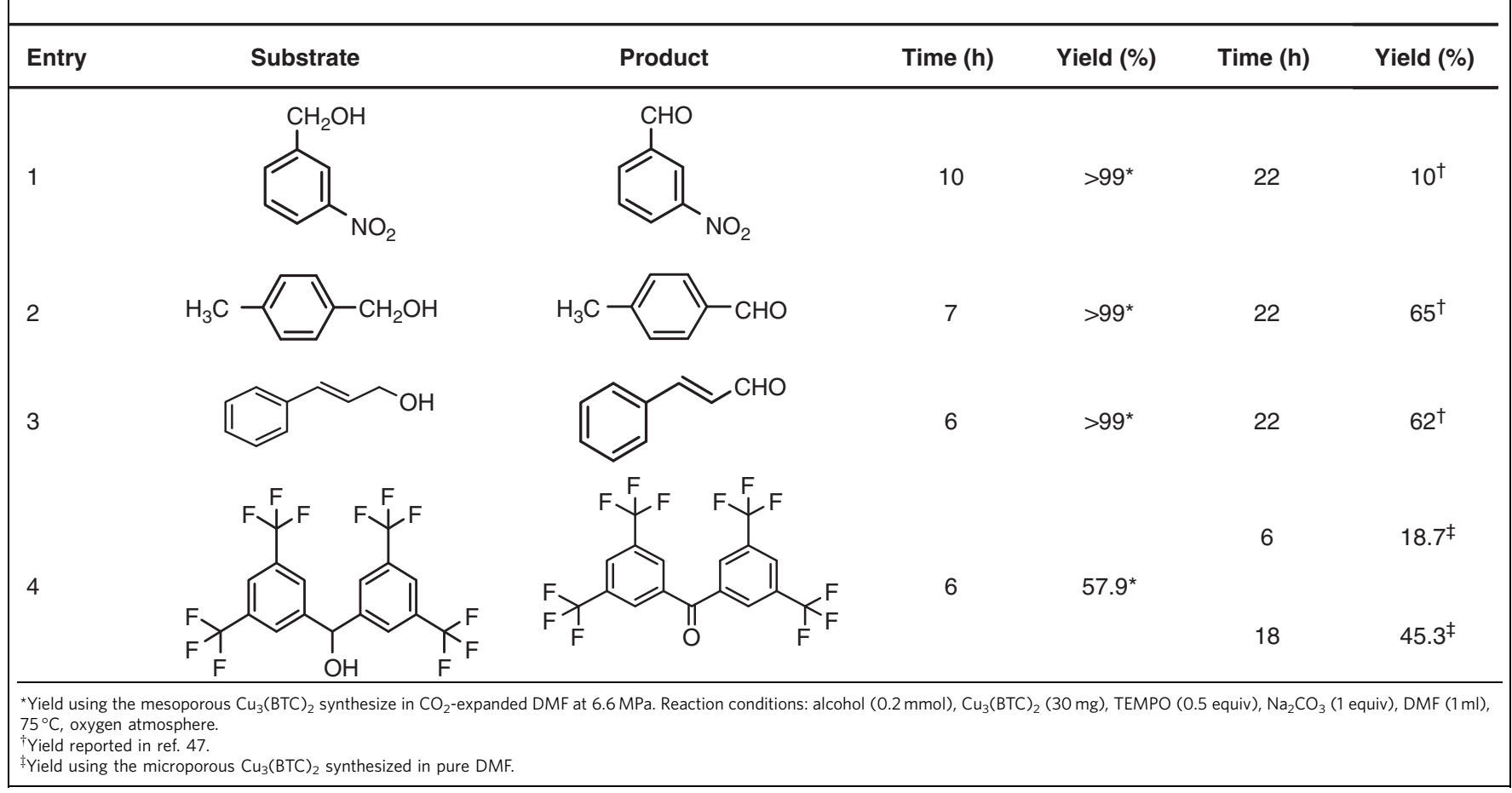


DMA and NMP were purchased from J\&K Scientific Co., Ltd. $\mathrm{Cu}(\mathrm{OAc})_{2} \cdot \mathrm{H}_{2} \mathrm{O}$ (A. R. Grade) was purchased from Alfa Aesar. $\mathrm{H}_{3} \mathrm{BTC}$ (purity $95 \%$ ) was provided by Aldrich. Benzene dicarboxylic acid $\left(\mathrm{H}_{2} \mathrm{BDC}, 98 \%\right), \mathrm{MnCl}_{2}(97 \%)$, methyl ammonium (30 wt $\% \mathrm{H}_{2} \mathrm{O}_{2}$ ), benzyl alcohol (99\%), cinnamyl alcohol (98\%) and TEMPO (purity 98\%) were supplied by Alfa Aesar. 3-Nitrobenzyl alcohol, 4-methylbenzyl alcohol and 3,3',5,5'-tetrakis(trifluoromethyl)benzhydrol (purity 97\%) were purchased from J\&K Scientific Co., Ltd. Sodium carbonate was provided by Beijing Chemical Reagent Company. The methyl ammonium salt of the ligand $\mathrm{H}_{2} \mathrm{BDC}$ was made by dissolving the benzene dicarboxylic acid in a $40 \mathrm{wt} \%$ solution of methyl amine in water. The excess methyl amine and water were evaporated under reduced pressure, and the isolated salt was then redissolved in distilled water to give an aqueous solution of desired concentration.

MOF synthesis. In a typical experiment, $\mathrm{H}_{3} \mathrm{BTC}(0.25 \mathrm{mmol})$ and $\mathrm{Cu}(\mathrm{OAc})_{2} \cdot \mathrm{H}_{2} \mathrm{O}(0.5 \mathrm{mmol})$ were added into the solvent $(5 \mathrm{~g})$, which was loaded in a stainless steel autoclave $(50 \mathrm{ml})$. Then $0.25 \mathrm{ml}$ triethylamine was added into the autoclave to deprotonate the linker. $\mathrm{CO}_{2}$ was charged into the cell under stirring until the desired pressure was reached. After the mixture was stirred at $30^{\circ} \mathrm{C}$ for $3 \mathrm{~h}$, the stirrer was stopped and the solvent was extracted by flowing $\mathrm{CO}_{2}$. The product was obtained after washing with ethanol for several times and drying at $60^{\circ} \mathrm{C}$ under vacuum for $24 \mathrm{~h}$. For comparison, the Cu-BTC MOF was synthesized in pure DMF, $\mathrm{H}_{3} \mathrm{BTC}(0.25 \mathrm{mmol})$ and $\mathrm{Cu}(\mathrm{OAc})_{2} \cdot \mathrm{H}_{2} \mathrm{O}(0.5 \mathrm{mmol})$ were added into DMF $(5 \mathrm{~g})$, which was loaded in a stainless steel autoclave $(50 \mathrm{ml})$. Then $0.25 \mathrm{ml}$ triethylamine was added into the autoclave to deprotonate the linker. After the mixture was stirred at $30^{\circ} \mathrm{C}$ for $24 \mathrm{~h}$, the stirrer was stopped. The product was obtained after centrifugation, washing with ethanol and drying at $60^{\circ} \mathrm{C}$ under vacuum for $24 \mathrm{~h}$.

For the synthesis of Mn-BTC MOF, $\mathrm{H}_{3} \mathrm{BTC}(0.5 \mathrm{mmol})$ and $\mathrm{MnCl}_{2}(0.5 \mathrm{mmol})$ were added into DMF $(5 \mathrm{~g})$, which was loaded in a stainless steel autoclave $(50 \mathrm{ml})$. Then $0.25 \mathrm{ml}$ triethylamine was added into the autoclave to deprotonate the linker. $\mathrm{CO}_{2}$ was charged into the cell under stirring until the desired pressure was reached. After the mixture was stirred at $30^{\circ} \mathrm{C}$ for $18 \mathrm{~h}$, the stirrer was stopped. The product was obtained after washing with ethanol and drying at $60^{\circ} \mathrm{C}$ under vacuum for $24 \mathrm{~h}$. For the synthesis of $\mathrm{Mn}-\mathrm{BDC} \mathrm{MOF}, \mathrm{MnCl}_{2}(0.5 \mathrm{mmol})$ and the methyl ammonium salt of the ligand $\mathrm{H}_{2} \mathrm{BDC}(0.5 \mathrm{mmol})$ were added into DMF $(5 \mathrm{~g})$, which was loaded in a stainless steel autoclave $(50 \mathrm{ml})$. The other experimental procedures and conditions were similar to those for the Mn-BTC MOF synthesis.

MOF characterization. The products were characterized by XRD (Model $\mathrm{D} / \mathrm{MAX} 2500$, Rigaka) with $\mathrm{Cu} \mathrm{K} \alpha$ radiation at a scanning rate of $5^{\circ} \mathrm{min}^{-1}$ The morphologies were characterized by a HITACHI S- 4800 scanning electron microscope. The porosity properties were gained from $\mathrm{N}_{2}$ adsorption-desorption isotherms using a Micromeritics ASAP 2020M system. Fourier transform infrared spectra were obtained using a Bruker Tensor 27 spectrometer, and the samples were prepared by the $\mathrm{KBr}$ pellet method. The thermogravimetric measurements were carried out using Pyris 1 TGA with $\mathrm{N}_{2}$ flow of $10 \mathrm{ml} \mathrm{min}^{-1}$. The SAXS experiment was carried out at Beamline 4B9A at Beijing Synchrotron Radiation Facility. The wavelength was $1.38 \AA$ and the distance of sample to detector was $2.044 \mathrm{~m}$.

Volume expansion. The apparatus and experimental procedures were similar to those reported previously $y^{50}$. It consisted mainly of a high-pressure view cell of $50 \mathrm{ml}$, a constant temperature water bath, a high-pressure syringe pump (DB-80), a pressure gauge, a magnetic stirrer and a gas cylinder. The temperature of the water bath was controlled by a HAAKE D8 digital controller and the accuracy of the temperature measurement was $\pm 0.05 \mathrm{~K}$. The pressure gauge was composed of a pressure transducer (FOXBORO/ICT, Model 93) and an indicator, which was accurate up to $\pm 0.025 \mathrm{MPa}$ in the pressure range of $0-20 \mathrm{MPa}$. In a typical experiment, the desired amount of organic solvent was added into the cell, and the cell was placed in the constant temperature water bath $\left(30^{\circ} \mathrm{C}\right)$. After the thermal equilibrium had been reached, a suitable amount of $\mathrm{CO}_{2}$ was charged into the high-pressure cell. The magnetic stirrer in the optical cell was started to accelerate the mixing of $\mathrm{CO}_{2}$ and the liquid. The pressure was unchanged with time as equilibrium was reached. The volume of the solution at equilibrium condition was known from the level of the liquid surface, and the volume expansion coefficient could be calculated on the basis of the volumes of the liquid before and after dissolution of $\mathrm{CO}_{2}$. More $\mathrm{CO}_{2}$ was charged and the volume of the liquid at another pressure was determined.

Catalytic test. The procedure of catalytic reaction was similar to those reported by Garcia and coworkers ${ }^{47}$. A $5 \mathrm{ml}$ flask was charged with the required amount of catalyst, TEMPO, and sodium carbonate. To this mixture, $1 \mathrm{ml}$ DMF was added followed by the appropriate quantity of alcohol. The mixture was stirred at $75^{\circ} \mathrm{C}$ under oxygen atmosphere. After the desired time, the heterogeneous mixture was cooled and centrifuged. The liquid product was analysed by a gas chromatograph (Agilent 6820). For the reusability investigation, after $3 \mathrm{~h}$ of reaction the catalyst was recovered by centrifugation, washed with ethanol and dried under vacuum. Then the solid was reused for a consecutive run.

\section{References}

1. Stock, N. \& Biswas, S. Synthesis of metal-organic frameworks (MOFs): Routes to various MOF topologies, morphologies, and composites. Chem. Rev. 112, 933-969 (2012).

2. Li, J.-R., Sculley, J. \& Zhou, H.-C. Metal-organic frameworks for separations. Chem. Rev. 112, 869-932 (2012).

3. Jin, S., Son, H.-J., Farha, O. K., Wiederrecht, G. P. \& Hupp, J. T. Energy transfer from quantum dots to metal-organic frameworks for enhanced light harvesting. J. Am. Chem. Soc. 135, 955-958 (2013).

4. Liu, Y., Xuan, W. \& Cui, Y. Engineering homochiral metal-organic frameworks for heterogeneous asymmetric catalysis and enantioselective separation. Adv. Mater. 22, 4112-4135 (2010).

5. Xuan, W., Zhu, C., Liu, Y. \& Cui, Y. Mesoporous metal-organic framework materials. Chem. Soc. Rev. 41, 1677-1695 (2012).

6. Qiu, L.-G. et al. Hierarchically micro- and mesoporous metal-organic frameworks with tunable porosity. Angew. Chem. Int. Ed. 47, 9487-9491 (2008).

7. Do, X. D., Hoang, V. T. \& Kaliaguine, S. MIL-53(Al) mesostructured metal-organic frameworks. Microporous Mesoporous Mater. 141, 135-139 (2011).

8. Choi, K. M., Jeon, H. J., Kang, J. K. \& Yaghi, O. M. Heterogeneity within order in crystals of a porous metal-organic framework. J. Am. Chem. Soc. 133, 11920-11923 (2011).

9. Sun, L.-B., Li, J.-R., Park, J. \& Zhou, H.-C. Cooperative template-directed assembly of mesoporous metal-organic frameworks. J. Am. Chem. Soc. 134, 126-129 (2012).

10. Perry, J. J., Perman, J. A. \& Zaworotko, M. J. Design and synthesis of metalorganic frameworks using metal-organic polyhedra as supermolecular building blocks. Chem. Soc. Rev. 38, 1400-1417 (2009).

11. Farha, O. K. \& Hupp, J. T. Rational design, synthesis, purification, and activation of metal-organic framework materials. Acc. Chem. Res. 43, 1166-1175 (2010).

12. Lykourinou, V. et al. Immobilization of MP-11 into a mesoporous metalorganic framework, MP-11@mesoMOF: A new platform for enzymatic catalysis. J. Am. Chem. Soc. 133, 10382-10385 (2011).

13. Deng, H. et al. Large-pore apertures in a series of metal-organic frameworks. Science 336, 1018-1023 (2012).

14. Liu, C., Li, T. \& Rosi, N. L. Strain-promoted 'Click' modification of a mesoporous metal-organic framework. J. Am. Chem. Soc. 134, 18886-18888 (2012).

15. Hong, D.-Y., Hwang, Y. K., Serre, C., Férey, G. \& Chang, J.-S. Porous chromium terephthalate MIL-101 with coordinatively unsaturated sites: surface functionalization, encapsulation, sorption and catalysis. Adv. Funct. Mater. 19, 1537-1552 (2009).

16. Fang, Q.-R. et al. Mesoporous metal-organic framework with rare etb topology for hydrogen storage and dye assembly. Angew. Chem. Int. Ed. 46, 6638-6642 (2007).

17. Yue, Y. et al. Template-free synthesis of hierarchical porous metal-organic frameworks. J. Am. Chem. Soc. 135, 9572-9575 (2013).

18. Zhao, Y. J. et al. Metal-organic framework nanospheres with well-ordered mesopores synthesized in an ionic liquid/ $\mathrm{CO}_{2} /$ surfactant system. Angew. Chem. Int. Ed. 50, 636-639 (2011).

19. Blanchard, L. A., Hancu, D., Beckman, E. J. \& Brennecke, J. F. Green processing using ionic liquids and $\mathrm{CO}_{2}$. Nature 399, 28-29 (1999).

20. Zhang, H. F., Long, J. \& Cooper, A. I. Aligned porous materials by directional freezing of solutions in liquid $\mathrm{CO}_{2}$. J. Am. Chem. Soc. 127, 13482-13483 (2005).

21. Zhang, J. L. \& Han, B. X. Supercritical or compressed $\mathrm{CO}_{2}$ as a stimulus for tuning surfactant aggregations. Acc. Chem. Res. 46, 425-433 (2013).

22. Jessop, P. G. \& Subramaniam, B. Gas-expanded liquids. Chem. Rev. 107, 2666-2694 (2007).

23. Goel, S. K. \& Beckman, E. J. Plasticization of poly(methyl methacrylate) (PMMA) networks by supercritical carbon dioxide. Polymer 34, 1410-1417 (1993).

24. Condo, P. D., Paul, D. R. \& Johnston, K. P. Glass transitions of polymers with compressed fluid diluents: Type II and III behavior. Macromolecules 27, 365-371 (1994).

25. Bortner, M. J. \& Baird, D. G. Absorption of $\mathrm{CO}_{2}$ and subsequent viscosity reduction of an acrylonitrile copolymer. Polymer 45, 3399-3412 (2004).

26. Gong, J. et al. Formation of nanoscale networks: Selectively swelling amphiphilic block copolymers with $\mathrm{CO}_{2}$-expanded liquids. Nanoscale 5, 1195-1204 (2013).

27. Hancu, D., Green, J. \& Beckman, E. J. $\mathrm{H}_{2} \mathrm{O}_{2}$ in $\mathrm{CO}_{2}$ : Sustainable production and green reactions. Acc. Chem. Res. 35, 757-764 (2002).

28. Beckman, E. J. Production of $\mathrm{H}_{2} \mathrm{O}_{2}$ in $\mathrm{CO}_{2}$ and its use in the direct synthesis of propylene oxide. Green Chem. 5, 332-336 (2003).

29. Phiong, H.-S., Cooper, C. G., Adesina, A. A. \& Lucien, F. P. Kinetic modelling of the catalytic hydrogenation of $\mathrm{CO}_{2}$-expanded $\alpha$-methylstyrene. J. Supercrit. Fluids 46, 40-46 (2008). 
30. Subramaniam, B. Gas-expanded liquids for sustainable catalysis and novel materials: Recent advances. Coord. Chem. Rev. 254, 1843-1853 (2010).

31. Andanson, J.-M., Marxa, S. \& Baiker, A. Selective hydrogenation of cyclohexenone on iron-ruthenium nano-particles suspended in ionic liquids and $\mathrm{CO}_{2}$-expanded ionic liquids. Catal. Sci. Technol. 2, 1403-1409 (2012).

32. Zhang, J. L., Han, B. X. \& Liu, J. C. Recovery of silver nanoparticles synthesized in $\mathrm{AOT} / \mathrm{C}_{12} \mathrm{E}_{4}$ mixed reverse micelles by antisolvent $\mathrm{CO}_{2}$. Chem. Eur. J 8, 3879-3883 (2002).

33. Yeo, S.-D. \& Kiran, E. Formation of polymer particles with supercritical fluids: A review. J. Supercrit. Fluids 34, 287-308 (2005).

34. Sala, S. et al. Crystallization of microparticulate pure polymorphs of active pharmaceutical ingredients using $\mathrm{CO}_{2}$-expanded solvents. Cryst. Growth Des. 12, 1717-1726 (2012).

35. West, K. N. et al. $\mathrm{CO}_{2}$-induced miscibility of fluorous and organic solvents for recycling homogeneous catalysts. Ind. Eng. Chem. Res. 43, 4827-4832 (2004).

36. Zhang, J. L. et al. Efficient separation of surfactant and organic solvent by $\mathrm{CO}_{2}$. Chem. Commun. 47, 5816-5818 (2011).

37. Chui, S. S.-Y., Lo, S. M.-F., Charmant, J. P. H., Orpen, A. G. \& Williams, I. D. A chemically functionalizable nanoporous material $\left[\mathrm{Cu}_{3}(\mathrm{TMA})_{2}\left(\mathrm{H}_{2} \mathrm{O}\right)_{3}\right]_{n}$. Science 283, 1148-1150 (1999).

38. Xiang, S., Zhou, W., Gallegos, J. M., Liu, Y. \& Chen, B. Exceptionally high acetylene uptake in a microporous metal - organic framework with open metal sites. J. Am. Chem. Soc. 131, 12415-12419 (2009).

39. Pham, M.-H., Vuong, G.-T., Fontaine, F.-G. \& Do, T.-O. A route to bimodal micro-mesoporous metal-organic frameworks nanocrystals. Cryst. Growth Des. 12, 1008-1013 (2012).

40. Deacon, G. B. \& Philips, R. Relationships between the carbon-oxygen stretching frequencies of carboxylato complexes and the type of carboxylate coordination. Coord. Chem. Rev. 33, 227-250 (1980).

41. Liu, J. et al. Experimental and theoretical studies of gas adsorption in $\mathrm{Cu}_{3}(\mathrm{BTC})_{2}$ : an effective activation procedure. J. Phys. Chem. C 111, 9305-9313 (2007).

42. Hartmann, M., Kunz, S., Himsl, D. \& Tangermann, O. Adsorptive separation of isobutene and isobutane on $\mathrm{Cu}_{3}(\mathrm{BTC})_{2}$. Langmuir 24, 8634-8642 (2008).

43. Tsao, C.-S. et al. Characterization of pore structure in metal-organic framework by small-angle X-ray scattering. J. Am. Chem. Soc. 129, 15997-16004 (2007).

44. Hafizovic, J. et al. The inconsistency in adsorption properties and powder XRD data of MOF-5 is rationalized by framework interpenetration and the presence of organic and inorganic species in the nanocavities. J. Am. Chem. Soc. 129, 3612-3620 (2007).

45. Tsuruoka, T. et al. Nanoporous nanorods fabricated by coordination modulation and oriented attachment growth. Angew. Chem. Int. Ed. 48 4739-4743 (2009).

46. Oh, M. \& Mirkin, C. A. Chemically tailorable colloidal particles from infinite coordination polymers. Nature 438, 651-654 (2005)
47. Dhakshinamoorthy, A., Alvaro, M. \& Garcia, H. Aerobic oxidation of benzylic alcohols catalyzed by metal-organic frameworks assisted by TEMPO. ACS Catal. 1, 48-53 (2011).

48. Carné, A., Carbonell, C., Imaz, I. \& Maspoch, D. Nanoscale metal-organic materials. Chem. Soc. Rev. 40, 291-305 (2011).

49. Park, K. H., Jang, K., Son, S. U. \& Sweigart, D. A. Self-supported organometallic rhodium quinonoid nanocatalysts for stereoselective polymerization of phenylacetylene. J. Am. Chem. Soc. 128, 8740-8741 (2006).

50. Zhang, J. L. et al. Effect of compressed $\mathrm{CO}_{2}$ on the size and stability of reverse micelles: Small-angle X-ray scattering and phase behavior study. J. Chem. Phys. 118, 3329-3333 (2003).

\section{Acknowledgements}

We thank the National Natural Science Foundation of China $(21173238,21133009$, U1232203, 21021003) and Chinese Academy of Sciences (KJCX2.YW.H16). We are also grateful to Prof. Zhonghua Wu, Prof. Zhihong Li and Dr Guang Mo of Beijing Synchrotron Radiation Facility for their help on small-angle X-ray scattering experiment.

\section{Author contributions}

L.P. performed the whole experiments. Z.M.X. and X.X.S. worked on the MOF characterization. C.C.L. and G.Y.Y. worked on the catalytic reaction. L.P., J.L.Z. and B.X.H. analysed the data and proposed the formation mechanism of mesoporous MOF J.L.Z. and L.P. wrote the manuscript. J.L.Z. conceived the project and designed the experiments.

\section{Additional information}

Supplementary Information accompanies this paper at http://www.nature.com/ naturecommunications

Competing financial interests: The authors declare no competing financial interests

Reprints and permission information is available online at http://npg.nature.com/ reprintsandpermissions/

How to cite this article: Peng, L. et al. Highly mesoporous metal-organic framework assembled in a switchable solvent. Nat. Commun. 5:4465 doi: 10.1038/ncomms5465 (2014).

(c) (1) (2) This work is licensed under a Creative Commons AttributionBY NC SA NonCommercial-ShareAlike 4.0 International License. The images or other third party material in this article are included in the article's Creative Commons license, unless indicated otherwise in the credit line; if the material is not included under the Creative Commons license, users will need to obtain permission from the license holder to reproduce the material. To view a copy of this license, visit http:// creativecommons.org/licenses/by-nc-sa/4.0/ 